\title{
Neurocognitive Processes of Recognition and Remembrance
}

\author{
Mukundan CR*, Sumit S and Chetan SM \\ Axxonet Brain Research Laboratory, Axxonet System Technologies, Bangalore, India
}

Submission: February 9, 2019; Published: February 19, 2019

*Corresponding author: Mukundan CR, Axxonet Brain Research Laboratory, Axxonet System Technologies, Bangalore, India.

\section{Opinion}

The article considers a brief comparison of the neurocognitive processes of recognition and remembrance, both of which may be affected several clinical conditions affecting brain. Measurement of these function related to remembrance could be also useful for the detection of presence of experiences related to autobiographic episodes, which renders one responsible in crime related activities, whereas recognition would help to know the familiarity of an individual with a person, place, or object.

Perception is the sensory process of registering sensory signals within the brain and identifying the source of the signals by comparing the signals with the already stored neuronal traces. The process comprises of directing attention to the source of the signals, and comparison of the registered model with the already existing memory traces for identifying a comparable sensory model, if present. The comparison would involve identifying any change from the already known neural models. The changes detected may contribute to a novelty effect of the new sensory inputs or familiarity with an already known neural model available in the brain. Recognition of the inputs using a comparable memory trace, if present would occur like a conditioned reflex [1]. In case there is no memory trace already available, one must learn to build a new internal trace or modify an existing model, which forms a primary learning process. Recognition of novelty or familiarity effects facilitate neural activation which produces a significant positivity, and the event related potential has been called the P300 potential, which could be recorded from the surface of the brain. The positivity representing detection appears within the range of 250 to 500 - 600 milliseconds after the sensory registration. The two other event related potentials which precede the P300 are the P1 representing sensory registration of signals, and N1 indicating direction of attention to the newly registered sensory event. An important experimental requirement is that the subject must make a response when any change in the stimulus inputs is detected.
P300 may be produced by detection of even small changes in a stimulus, if the same stimulus is infrequently, but repeatedly presented. For example, if a different stimulus is presented every time, a P300 will be elicited every time. If one of the stimuli presented is a repetition of the previous one, detection of the repetition will produce a higher $\mathrm{P} 3$, marking that the brain of the subject has realized the repetition of a stimulus. Several studies have differentiated two components of P300 as a and $b$, where ' $a$ ' has been identified representing a novelty effect, whereas ' $b$ ' represents the regular recognition of a new stimulus. The potential could easily be detected either with auditory or visual stimuli, and it could be recorded as a regular clinical test, as changes in the potential are detected in most of brain lesion cases, especially if the lesion has affected the frontal lobe functions. Auditory Brainstem Responses are yet another regular group of clinically significant measures, generated from the subcortical levels, which take place well before sensory registration at the cortical level occurs.

Another important neurocognitive processing in the brain is indeed related to encoding and decoding, when meanings are assigned to words and other symbols heard and seen, and a cumulative meaning is derived or created. Along with these processes, yet another significant neurocognitive process that takes place in the brain is that of remembrance of information, stored in the past. These may belong to the experiences one would have had, or mere knowledge acquired by the individual. Remembering past events is significantly different from the mere retrieval of information from the knowledge bank for recognition. Remembrance was differentiated from knowing, where knowing is essentially recognizing. Recognition could occur when the stimuli are presented in any sensory modality, whereas remembrance of an autobiographic episode would occur, only when it is cued by a short statement, or an individual is again subjected to a similar or comparable experience. 
The initial neural processes in remembrance also deals with recognition of the inputs. Mandler [2] was the first to differentiate knowing from remembering. Remembrance requires several accompanying functions such internal direction of attention, accessing source memory or reference to the place and time of occurrence of a happening or experience, accessing sensory-motor imageries or experiences, which may include recreation of imageries in the visual, auditory, motor, and touch sensations, whichever one would have had experienced, and the accompanying emotional experiences one would have had. Remembrance is therefore reliving an earlier experience by reloading or recreating the virtual memories of the original event or experience. This was supported in several neuroimaging studies by Tulving [3-4] and in many other studies [5-11]. Neural equivalents of several of the neural imaging changes seen during remembrance could also detected in EEG, supporting the presence of remembrance of an earlier experience taking place. However, these changes may occur over a longtime epoch, and our studies have shown several neural changes within the frontal - no frontal cortical domain, related to a remembrance may occur any time within 7 secs, after cueing the person about a specific component of the earlier experience. Long remembrance cued be cued by sequence of probes referring to a previous event, provided the person has had the experience.

There is no comparison between the neural activation patterns between that of mere recognition and remembrance. Recognition of a component needs to be accomplished only by knowing about it, which could be acquired through several indirect means of acquisition, without any experiential contacts. Further, the neural indicator is only an event related potential, which could be recorded from any of the several brain surface electrodes. On the other hand, remembrance occurs only when one has had the experiential participation in an event, and there are multiple topographically specific changes occurring over a long period of several seconds, which are seen in multiple electrodes, during each remembrance. The multichannel EEG need to be analyzed in a nonlinear manner for detecting the significant change in the power values in different frequency bands, as well as Event Related Potentials, all of which may sequentially occur at different points in time, generally over 5-7 secs. These changes are seen mainly in the frontal areas and associated non-frontal areas, which contribute to recreation of sensory and motor imageries, during remembrance [811]. Testing remembrance may be clinically useful for the early detection of loss of remembrance, as in dementia, and for forensic applications to find if the concerned person has had any specific previous experience, which could be cued by sequentially presented verbal probes. The probes could be presented at regular interval, which the subject needs only listen to, without giving any response.

\section{References}

1. Sokolov EN (1963) Perception and the Conditioned Reflex. Oxford, Pergamon, Turkey.

2. Mandler G (1980) Recognizing: The judgment of prior occurrence. Psychological Review 87: 252-271.

3. Tulving E (1989) Memory: Performance, knowledge and experience. European J of Cog Psychol 1: 3-26.

4. Tulving E (1987) Multiple memory systems and consciousness. Hum Neurobiol 6: 67-80.

5. Mukundan CR (2007) Brain Experience: Neuroexperiential Perspectives of Brain-Mind. Atlantic Publishers, New Delhi, India.

6. Mukundan CR (2015) Brain at Work: Neuroexperiential Perspectives. Atlantic Publishers. New Delhi, India.

7. Mukundan CR (2017) Emotion-The Driving Force. Red Shine Publication, Ahmedabad, India.

8. Tulving E (1972) Episodic and semantic memory. In: E Tulving and W Donaldson (Eds.) Organization of Memory, Academic Press, New York, pp. 381-403.

9. Schacter DL, Harbluk JL, McLachlen DR (1984) Retrieval without recollection: an experimental analysis of source amnesia. Journal of Verbal Learning and Verbal Behaviour 23(5): 593-611.

10. Milner B, Petrides M, Smith ML (1985) Frontal lobes and the temporal organization of memory. Hum Neurobiol 4(3):137-142.

11. Clayton NS, Dickinson A (1998) Episodic-like memory during cache recovery by scrub jays. Nature 395(6699): 272-274.

\section{Your next submission with Juniper Publishers will reach you the below assets}

- Quality Editorial service

- Swift Peer Review

- Reprints availability

- E-prints Service

- Manuscript Podcast for convenient understanding

- Global attainment for your research

- Manuscript accessibility in different formats

( Pdf, E-pub, Full Text, Audio)

- Unceasing customer service

Track the below URL for one-step submission https://juniperpublishers.com/online-submission.php 